\title{
Adsorption Properties and Breakthrough Model of Formaldehyde on Bone Char
}

\author{
Abbas Rezaee, Hossin-Ali Rangkooy, Ali Khavanin, Ahmad Jonidi-Jafari, Reza Darvish Cheshma \\ Soltani, and Afshin Nili-Ahmadabadi
}

\begin{abstract}
The objective of this investigation was to study the adsorption of formaldehyde $\left(\mathrm{CH}_{2} \mathrm{O}\right)$ vapor on bone char (BC) using isotherm models. The $\mathrm{BC}$ as an adsorbent was produced from cattle and sheep bones by pyrolysis in furnace. The adsorption breakthrough time and the equilibrium adsorption capacity of $\mathrm{CH}_{2} \mathrm{O}$ on $\mathrm{BC}$ were studied. The Yoon and Nelson model was applied to investigate the breakthrough behavior of $\mathrm{CH}_{2} \mathrm{O}$ vapor on $\mathrm{BC}$ columns for breakthrough fraction less than $50 \%$. The $k^{\prime}$ and $t$ values were used to calculate the entire breakthrough curve regarding the adsorption of $\mathrm{CH}_{2} \mathrm{O}$ vapor on BC columns. The maximum value of the BET, apparent density and the average pore size for the $B C$ were $105.24 \mathrm{~m}^{2} / \mathrm{g}$, $0.645 \mathrm{~g} / \mathrm{cm}^{3}$ and $13.95 \mathrm{~nm}$, respectively. The $50 \%$ breakthrough time $t$ decreases with increasing $\mathrm{CH}_{2} \mathrm{O}$ inlet concentration. The experimental data were found to fit well to Langmuir isotherm in term of obtained $R^{2}$ value $(0.999)$. The obtained $q_{\max }$ (maximum adsorption capacity) parameter for formaldehyde vapor adsorption was $290.11 \mathrm{mg} / \mathrm{g}$. The results suggest that BC could be used as a suitable adsorbent for the removal of formaldehyde in gaseous phase by adsorption process.
\end{abstract}

Index Terms-Adsorption, Breakthrough time, Formaldehyde, Bone Char

\section{INTRODUCTION}

Formaldehyde $(\mathrm{CH} 2 \mathrm{O})$ is one of the common air pollutants [1]. It usually produces in chemical industries for the production of more complex compounds and building materials such as pressed wood, wallpaper, paint etc. Formaldehyde is also one of the principal ingredients of cigarette smoke. The formaldehyde emissions from these sources can continue for a long time after original product manufacture. Occupants mainly expose to this gas by inhalation, which may cause headaches, a sensory irritation, and difficulty breathing, nausea, coryza, pharyngitis, emphysema, lung cancer, aggravating asthma symptoms and even death [1-3]. Moreover, formaldehyde has been classified as a human carcinogen by the International Agency for Research on Cancer (IARC) [4]. Therefore, decontamination of ambient air from this toxic gas is critical for improving indoor air quality and human health. There are different processes that are commonly used in industry to

Manuscript received August 22, 2011, revised October 10, 2011. This work was supported in part by the Tarbiat Modares University.

A. Rezaee, H-A. Rangkooy, A. Khavanin, A. Jonidi Jafari, R. Darvishi Cheshmeh Soltani and A. Nili-Ahmadabadi are with the Department of Environmental Health, Faculty of Medical Sciences, Tarbiat Modares University, Tehran, Iran (e-mail: rezaee@ modares.ac.ir). remove volatile organic compounds (VOCs) vapor such as photocatalytic oxidation and adsorption process $[1,5]$. They are usually classified in two groups: oxidation method and recovery method. Oxidation method is expensive and energy exhausting. The recovery methods to recover the used organic solvents in the air are condensation, adsorption by adsorbents, ion-exchange and membrane technology [6]. Among these methods, the adsorption method is considered as the most promising technology in view point of organic compound recovery and energy savings. The carbonaceous adsorbents were widely used for adsorption of formaldehyde from atmosphere. Adsorption using activated carbons as carbonaceous adsorbents has been shown to be one of the most efficient procedures in the elimination of VOCs from wastewater. However, activated carbons are expensive materials which require complex activation processes, and it is therefore mandatory, from an economic point of view, to regenerate them and to reuse them. The adsorption efficiency is governed by characteristics of adsorbate and adsorbent. Therefore, it is very important to choose the appropriate adsorbent $[2,7]$. The formaldehyde is not efficiently removed by the conventional activated carbon. Some pollutants were removed from aqueous solution using bone char (BC) as an adsorbent material [8]. The $\mathrm{BC}$ has been used extensively as an adsorbent for the decolorization of cane sugar and to a lesser extent for the defluoridation of drinking water. The quality of the $\mathrm{BC}$ is usually controlled by the amount of oxygen present in the charring atmosphere. It consists mainly of calcium phosphate and a small amount of carbon. $\mathrm{BC}$ is a mixed compound adsorbent in which carbon is distributed throughout the porous structure of hydroxyapatite $(\mathrm{Ca} 10(\mathrm{PO} 4) 6(\mathrm{OH}) 2$ or CaHAP). The physical and chemical properties of CaHAP have been widely reported.The studies show that the removal mechanism provide not only an adsorption effect but also a type of ion exchange reaction between the ions in solution and calcium ions of the apatites[11, 12]. After use it is regenerated by washing and calcining so that the $\mathrm{BC}$ can pass through many operating cycles before its activity has decreased to an unacceptably low level. Wide variety of different materials has been proposed for the sorption of pollutants [9]. It has recently been suggested that poorly cryctallized apatite, such as BC apatite, might represent a low-cost and readily available phosphate source that could be used to as adsorbent [10]. To the best of our knowledge, there are no existing reports that have investigated formaldehyde removal from air using $\mathrm{BC}$ as an adsorbent. The Yoon and Nelson equation was developed by a simple model addressing the adsorption and the breakthrough of adsorbate vapors or gases. The Yoon and 
Nelson model not only is less complicated than other presented model, but also requires no detailed data concerning the characteristics of the adsorbate. In this study, we developed a new adsorbent to adsorb the formaldehyde vapor. The $\mathrm{BC}$ was produced from cattle and sheep bones. The $\mathrm{BC}$ was used as an inexpensive adsorbent to investigate the removal efficiency of formaldehyde and to determine breakthrough time.

\section{MAterials AND MethodS}

\section{A. Experimental Procedure}

Formaldehyde solution $(37.0 \% \mathrm{w} / \mathrm{w})$ was procured from Merck, India. Double distilled water was used for all the measurements. Deionized water was used for washing of all glassware and solids. The BC was made from cattle and sheep bones. First, the bone from cattle and sheep was crushed into pieces of $10-15 \mathrm{~cm}$ in length, rinsed three times in deionized water for $4 \mathrm{~h}$ to remove fate and residual protein pieces. The bone then dried at $110^{\circ} \mathrm{C}$ over night and cooled in desiccators, and divided into two portions for pyrolysis. Pyrolises of bone was performed in a rectangular furnace that was externally heated by electric power source. The bones were inserted in furnace to product $\mathrm{BC}$ at $450^{\circ} \mathrm{C}$ for $4.5 \mathrm{~h}$. The solids yield from the pyrolysis were transport to a desiccators and cooled to room temperature. The $\mathrm{BC}$ was pulverized and sieved using standard sieves whit the range between 20 to 40 mesh. Finally, deionized water was used to wash obtained BC. The formaldehyde vapor was generated by flowing air through the formaldehyde solution to the adsorption column. The concentrations of gaseous formaldehyde generated in the experiment were 20,50,100 and 200 ppmv, respectively. The $\mathrm{BC}$ with the average particle size of $0.63 \mathrm{~mm}$ were dried at $110^{\circ} \mathrm{C}$ in a vacuum oven for at least $24 \mathrm{~h}$. The column temperature was maintained at $25^{\circ} \mathrm{C}$ throughout the experiment. In the present study, breakthrough time measurements have been made with a constant contact time for all experiments. The experiment was carried out until equilibrium time. When the effluent concentration of the formaldehyde reached its specified influent concentration (i.e., $100 \%$ of breakthrough), the concentration measurement of the effluent gas was stopped. This study intends to investigate the adsorption behavior of formaldehyde in the BC column, and to develop a procedure on the basis of the Yoon and Nelson breakthrough model for predicting the useful life of a adsorbent. Some of the adsorbate molecules adsorb on functional groups of the adsorbent and others pass through the adsorbent bed. Yoon and Nelson model describes the relationship between the probability for adsorption and the probability for breakthrough as below equation [13]:

$$
P=1-Q=C b / C i,
$$

where $C_{\mathrm{b}}$ and $C_{\mathrm{i}}$ are the breakthrough (effluent) concentration $\left(\mathrm{kg} / \mathrm{m}^{3}\right)$ and influent concentration $\left(\mathrm{kg} / \mathrm{m}^{3}\right)$ of the adsorbate, respectively. The $Q$ and $P$ are also the probability for adsorption and probability for breakthrough, respectively. It is reasonably assumed that the rate of change in the breakthrough concentration, $d C \mathrm{~b} / d t$, is proportional to $\mathrm{Cb}$ and to the number of adsorptive sites according to below equation:

$$
2 d Q / d t=k^{\prime} Q(1-Q)
$$

where $k^{\prime}$ is a rate constant $\left(\mathrm{min}^{-1}\right)$. To obtain an explicit expression, the solution of the differential equation (2) is solved by using the integration approach.

$$
\text { Ln } Q / 1-Q=k^{\prime}(t-t)
$$

where $t$ is the time required to obtain $50 \%$ breakthrough (i.e., $Q=0.5$ ). Rearranging Eq. (3), one obtains an expression for the breakthrough (sampling) time $(t)$ in terms of the influent concentration $\left(C_{\mathrm{i}}\right)$ and the breakthrough concentration $\left(C_{\mathrm{b}}\right)$ :

$$
\mathrm{t}=t+1 / k^{\prime} \ln \left[C_{\mathrm{b}} / C_{\mathrm{i}}-C_{\mathrm{b}}\right]
$$

According to Eq. (4), the value of $k^{\prime}$ can be obtained from the slope of the plot $\ln \left[C_{\mathrm{b}} /\left(C_{\mathrm{i}}-C_{\mathrm{b}}\right)\right]$ versus breakthrough time $t$, and the value of $t(50 \%$ breakthrough time $)$ can be determined as the time at $Q=0.5$ (i.e., $C_{\mathrm{b}}=C_{\mathrm{i}} / 2$ ). Following the determination of $k^{\prime}$ and $t$, one may generate the complete breakthrough curve for a given set of experimental conditions by applying Eq. (4). Moreover, Yoon and Nelson have introduced the following equation:

$$
K=k^{\prime} t
$$

where $k$ is a proportionality constant for a given adsorbate and specified type of adsorbent. They indicated that $k$ is independent of adsorbate concentration and flow rate. On the other hand, both $k^{\prime}$ and $t$ are dependent on the concentration of the adsorbate and the flow rate [13]. The equilibrium adsorption capacity of adsorbed formaldehyde on the adsorbent was calculated using below equation:

$$
q=\left(C_{\mathrm{i}}-C\right) / w \times V
$$

where $q$ is the equilibrium adsorption capacity $(\mathrm{mg} / \mathrm{g}), C_{\mathrm{i}}$ and $C$ are the initial and final concentration of formaldehyde $\left(\mathrm{mg} / \mathrm{m}^{3}\right)$, respectively, and $v$ is the volume of air $\left(\mathrm{m}^{3}\right)$.

\section{B. Reactor set-up}

Fig.1 displays the schematic diagram of the adsorption system for adsorption of formaldehyde in continuous flow mode.

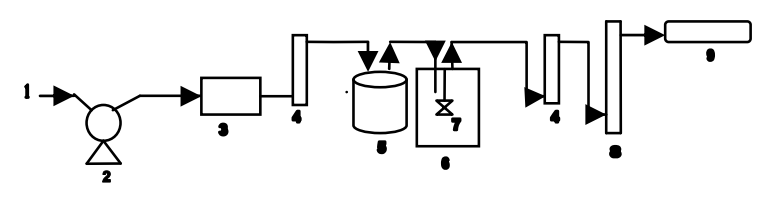

Fig.1. Schematic diagram for adsorption of gaseous formaldehyde.(1)clean air (2) air pump; (3) drier; (4) flow meters; (5) formaldehyde solution; (6) mixer; (7) electric fan; (8) fixed-bed adsorption column; (9) detector.

The system consists of three sections: feed system, adsorption column and gas detection apparatus. The feed system includes air pump, dehumidifier, rotameters, and a 
mixer equipped to an electric fan, which can adjust and control the inlet concentration of formaldehyde in the feed. The adsorption column was made from pyrex glass tubing (5mm inside diameter and $100 \mathrm{~mm}$ in length). The average weight of adsorbent loaded in the column was around $100 \mathrm{mg}$. The formaldehyde vapor was generated by flowing air through the formaldehyde solution to the adsorption column.

\section{Analysis}

The solids structure of the bone char were analyzed using $\mathrm{X}$-Ray diffraction (Philips) and scanning electron microscopy (XL,30 Philips). The detection system consists of The PhoCheck 5000 PID and humidity meter, which can analyze the formaldehyde concentration and the relative humidity of the column.

\section{RESULTS AND DiSCUSSION}

\section{A. Adsorbent Characteristics}

Some properties of the adsorbents are presented in table I. Specific surface areas and total pore volumes of the $\mathrm{BC}$ was determined with the BET. The results show that total pore volume and specific surface area of $\mathrm{BC}$ was high.

TABLE I: BC CHARACTERISTICS

\begin{tabular}{ccccc}
\hline Composition & $\begin{array}{c}\text { Total pore } \\
\text { volume }\left(\mathrm{cm}^{3} /\right. \\
\mathrm{g})\end{array}$ & $\begin{array}{c}\text { Specific } \\
\text { surface } \\
\text { area } \\
\left(\mathrm{m}^{2} / \mathrm{g}\right)\end{array}$ & $\begin{array}{c}\text { Apparent } \\
\text { density }\left(\mathrm{g} / \mathrm{cm}^{3}\right)\end{array}$ & $\begin{array}{c}\text { pore } \\
\text { size }(\mathrm{nm})\end{array}$ \\
\hline $\mathrm{BC}$ & 0.367 & 105.24 & 0.645 & 13.95 \\
\hline
\end{tabular}

The surface structure of the black bone char was analyzed using a scaning electron microscopy (SEM). The SEM micrograph with 5000x magnification is shown in Fig. 2. The SEM micrograph show the high porosity of $\mathrm{BC}$ for effective formaldehyde adsorption. The X-Ray Differaciton analysis revealed that the $\mathrm{BC}$ is a mixed adsorbent composed of basic tricalcium phosphate and amorphous carbon (Fig.3). The calcium phosphate is in the hydroxyapatite form. The amorphous carbon fraction is distributed throughout the whole of the entire hydroxyapatite but most of the carbon exists as a highly active thin film that covers the porous hydroxyapatite surface.

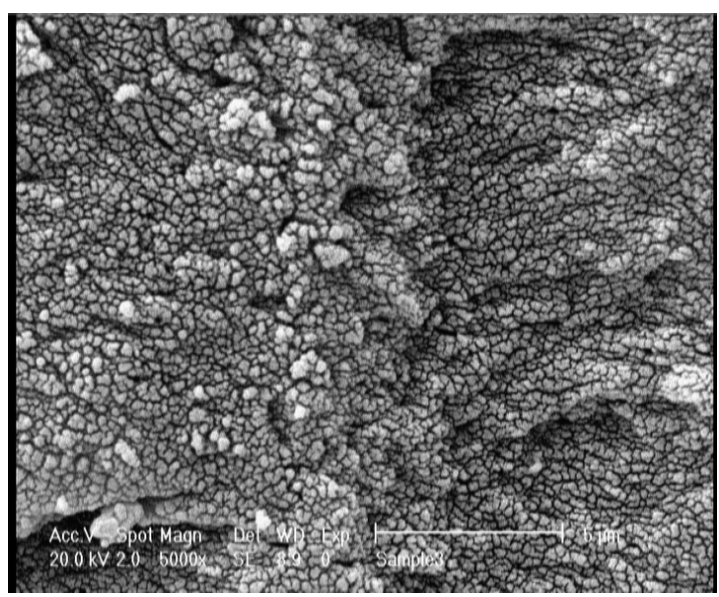

Fig.2. Scanning electron microgtaph of $\mathrm{BC}$

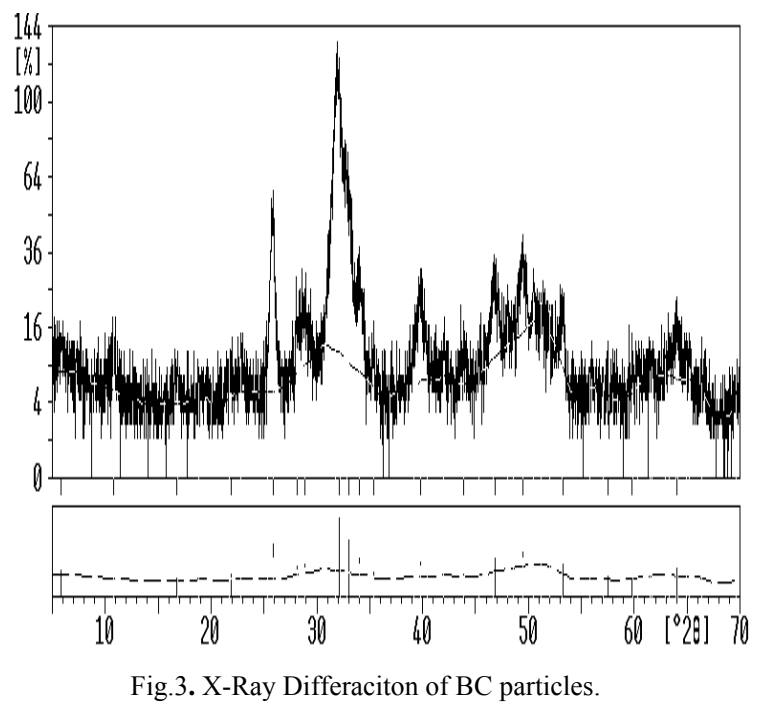

\section{B. Breakthrough Time Determination}

Breakthrough time determination was carried out by varying the inlet concentration of formaldehyde from 20 to $200 \mathrm{ppmv}$ at a constant flow rate of $500 \mathrm{ml} / \mathrm{m}^{3}$. To depict the breakthrough curves of formaldehyde vapor on BC, $100 \mathrm{~g}$ of the adsorbent were placed in a column at a temperature of $25^{\circ} \mathrm{C}$ and the breakthrough percent was plotted versus time, as shown in Fig. 4. The outlet concentration of adsorbate is zero at the beginning of the experiment, but after beginning breakthrough phenomenon the outlet concentration of formaldehyde increases gradually with increasing time [14].

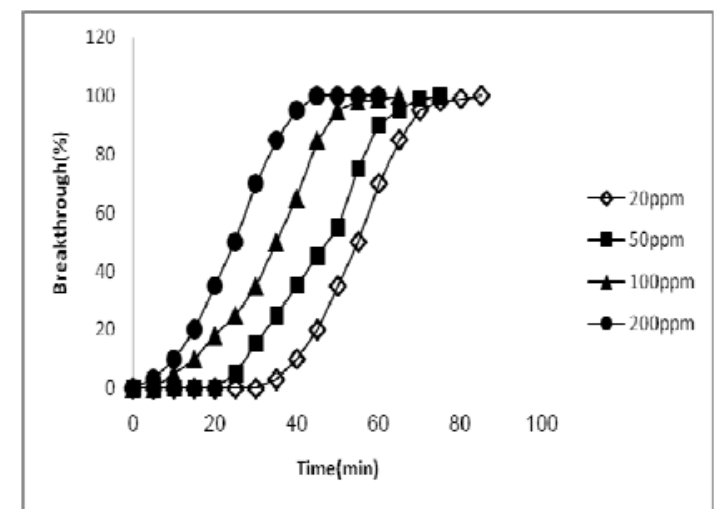

Fig.4. Typical breakthrough curves of formaldehyde adsorption on $\mathrm{BC}$ at various concentrations and constant temperature of $25^{\circ} \mathrm{C}$.

TABLE II: EFFECT OF INLET CONCENTRATION OF ADSORBATE ON EQUILIBRIUM TIME AND ADSORPTION CAPACITY

\begin{tabular}{llll}
\hline Adsorbent & $\mathrm{Ci}(\mathrm{ppmv})$ & te $(\min )$ & $\mathrm{q}(\mathrm{mg} / \mathrm{g})$ \\
\hline \multirow{3}{*}{$\mathrm{BC}$} & 20 & 85 & 154.43 \\
& 50 & 75 & 212.31 \\
& 100 & 65 & 251.42 \\
& 200 & 45 & 275.78 \\
\hline
\end{tabular}

As shown in the figure, the higher inlet concentration of the adsorbate was, the faster breakthrough was. In Fig. 4, equilibrium time $\left(t_{e}\right)$ is defined as time when outlet concentration is $100 \%$ of inlet concentration. The equilibrium time and adsorption capacity $\left(\mathrm{q}_{\mathrm{e}}\right)$ according to inlet concentration obtained from Fig. 4 were listed in Table II. As inlet concentration of formaldehyde vapor on fixed-bed BC in column increased from 20 ppmv to 200 
ppmv, the equilibrium time decreased from $85 \mathrm{~min}$ to $45 \mathrm{~min}$. With the increase of formaldehyde concentration from 20 to $200 \mathrm{ppm}$, the adsorption capacity (as $\mathrm{mg} / \mathrm{g}$ ) increased from 154.43 to $275.78 \mathrm{mg} / \mathrm{g}$ for formaldehyde adsorption onto BC, respectively.Therefore, as the inlet concentration of formaldehyde vapor increased, the equilibrium time decreased, but the equilibrium adsorption capacity $\left(\mathrm{q}_{\mathrm{e}}\right)$ of adsorbent increased. The slower breakthrough time under lower concentration of formaldehyde showed the importance of intra-particle diffusion in adsorption process [15].

\section{Isotherm Study}

The adsorption isotherm is to illustrate the equilibrium adsorption capacity at constant temperature according to concentration of adsorbate. The equilibrium between adsorbed formaldehyde and free formaldehyde in air can be described by adsorption isotherm models such as the Langmuir and Freundlich model. Eq.(7) illustrates the linear form of the Langmuir isotherm model:

$$
C_{\mathrm{e}} / q_{\mathrm{e}}=1 / K_{\mathrm{L}} q_{\max }+1 / q_{\max } C \mathrm{e}
$$

where $q_{e}(\mathrm{mg} / \mathrm{g})$ is the amount of adsorbed formaldehyde per unit weight of adsorbent and $C_{e}(\mathrm{mg} / \mathrm{L})$ is concentration of free formaldehyde in air. $Q_{m}(\mathrm{mg} / \mathrm{g})$ is the amount of adsorbate per unit weight of adsorbent and $K(\mathrm{~L} / \mathrm{mg})$ is related to the affinity of the binding sites. By plotting Ce/qe versus $C$, a straight line with slope $1 / q_{\max }$ and intercept $1 / K_{\mathrm{L}} q_{\max }$ could be achieved. The Freundlich isotherm is an empirical equation based on a heterogeneous surface. The linear form of the Freundlich isotherm model is shown in Eq.(8):

$\log q_{\mathrm{e}}=\log K_{\mathrm{F}}+1 / n \log C_{\mathrm{e}}$

where $n$ and $K_{\mathrm{F}}$ are the Freundlich constants, and are related to the adsorption intensity and adsorption capacity, respectively. Adsorption isotherms of of formaldehyde vapor on black bone char carried out at $25^{\circ} \mathrm{C}$ are compared in Fig. 5. As shown in Fig.5, equilibrium adsorption capacity $\left(\mathrm{q}_{\mathrm{e}}\right)$ increased with the increase of formaldehyde concentration. The values of the isotherm constants and maximum adsorption capacity $\left(q_{\max }\right)$ are provided in Table 3 . As shown in Table III, the values of the correlation coefficients indicated that the Langmuir model was more suitable than the Freundlich model for formaldehyde adsorption onto black bone char. The results indicated that the maximum formaldehyde adsorption capacity $\left(\mathrm{q}_{\max }\right)$ of black bone char was $290.11 \mathrm{mg} / \mathrm{g}$. With compare to the other study, maximum adsorption capacity of BC was relatively high. Shiue et al. in their study reported the maximum adsorption capacity $\left(\mathrm{q}_{\max }\right)$ of coconut-based granular activated carbon for toluene adsorption was $175 \mathrm{mg} / \mathrm{g}$ at the best conditions (face velocity of $0.114 \mathrm{~m} / \mathrm{s}$ ) [16]. This result could be explained by the amount of carbon in structure of BC. The carbon exists as a highly active thin film that covers the porous hydroxyapatite surface. Langmuir isotherm was applied for the evaluation of maximum adsorption capacity corresponding to complete monolayer coverage on the adsorbents. Therefore, the formaldehyde adsorption onto BC could be a monolayer adsorption onto a homogeneous surface of the adsorbent, despite of Freundlich adsorption isotherms that describe a monolayer adsorption onto a heterogenous surface of the adsorbent.

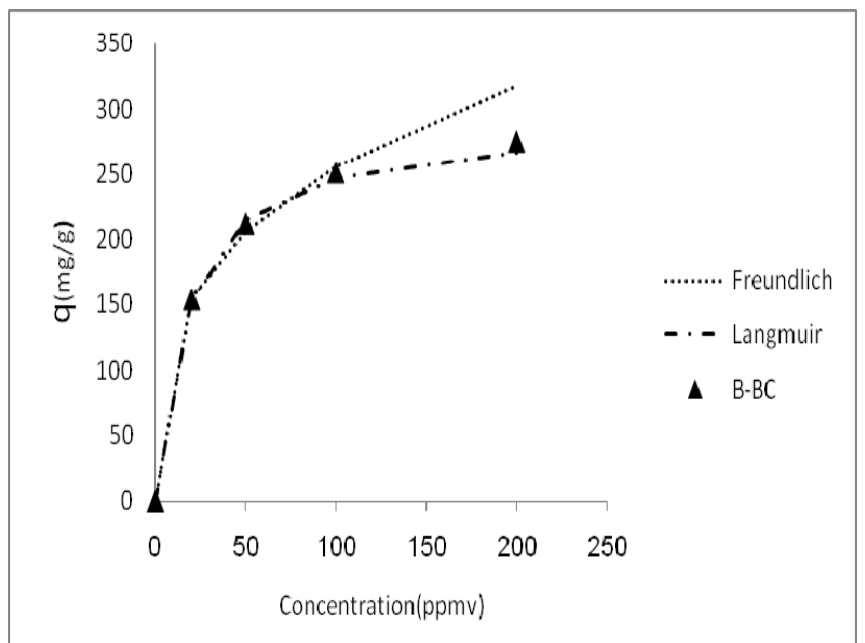

Fig.5. Adsorption isotherm of formaldehyde vapor on black bone char at $25^{\circ} \mathrm{C}$.

TABLE III: ISOTHERM PARAMETERS FOR FORMALDEHYDE ADSORPTION

\begin{tabular}{lllllll}
\hline \multirow{2}{*}{ Adsorbent } & \multicolumn{2}{l}{ Langmuir parameters } & \multicolumn{3}{l}{ Freundlich parameters } \\
\cline { 2 - 7 } & $\begin{array}{llllll}q_{\max } \\
(\mathrm{mg} / \mathrm{g})\end{array}$ & $\begin{array}{l}K_{\mathrm{L}} \\
(\mathrm{l} / \mathrm{mg})\end{array}$ & $R^{2}$ & $\begin{array}{l}K_{\mathrm{F}} \\
(\mathrm{mg}(1-1 / n)\end{array}$ & $n$ & $R^{2}$ \\
& & & & $11 / \mathrm{n} / \mathrm{g})$ & \\
& 290.11 & 0.0576 & 0.99 & 61.2895 & 3.2 & 0.78 \\
BC & & 9 & & 2 & 1 \\
\hline
\end{tabular}

\section{Yoon and Nelson Model}

In this study, the relationship between sampling time $(t)$ and breakthrough fraction (i.e., $C_{\mathrm{b}} / C_{\mathrm{i}}$ ) was investigated for each concentration of formaldehyde at constant temperature of $25^{\circ} \mathrm{C}$. It should be noted that breakthrough fraction is a function of sampling time according to Eq. (4). A typical illustration of the application of Eq. (4) is depicted in Figs. 6 based on the experimental data of breakthrough for $\mathrm{CH}_{2} \mathrm{O}$ in the concentration ranging from 20 to $200 \mathrm{ppmv}$ at $25^{\circ} \mathrm{C}$. As predicted by the Yoon and Nelson model (Eq. 4), the plots of the Figs.6 yielded straight lines with a slope of $k^{\prime}$ and intercept of $-k$. As shown in Figs, the model appears to fit the experimental data reasonably well. Thus, the rate constant $k^{\prime}$ and $50 \%$ breakthrough time $t$ can be calculated by fitting a straight line. The least-squares method has been used to give these values as listed in Table 4 . The values of $k$, computed from Eq. (5), are also listed in Table IV. As expected from the Yoon and Nelson model [13], both $k^{\prime}$ and $t$ are dependent on the adsorbate inlet concentration. As shown in Table 4, the rate constant $k^{\prime}$ increases with increasing adsorbate inlet concentration from $50 \mathrm{ppm}$ to $200 \mathrm{ppm}$, whereas the $50 \%$ breakthrough time $(t)$ with increasing inlet concentration of formaldehyde from 20 to $200 \mathrm{ppm}$ decreases. Following the determination of the values of $k^{\prime}$ and $t$, the complete breakthrough curves can be generated for a given set of experimental conditions by substituting the determined values of $k^{\prime}$ and $t$ (Table 4) into Eq. (4). The calculated 
theoretical curves are compared with the corresponding experimental data in Fig.4. It is demonstrated that the agreement between the Yoon and Nelson model and the experimental data is high. This is reasonable if one notes that the solid lines in Figs. 4 represent the lines with the best fit, which have good correlation coefficient $\left(\mathrm{R}^{2}\right)$ ranging from 0.9583 to 0.9953 , for formaldehyde adsorption onto BC. The proposed model by Yoon and Nelson shows the rate of decrease in the probability of adsorption for each adsorbate is corresponding to the probability of adsorption of an adsorbate and the probability of breakthrough of the adsorbate [16].

TABLE IV: VALUES OF THE THEORETICAL PARAMETERS $K ', T$, AND $K$ FOR ADSORPTION OF FORMALDEHYDE ADSORPTION ON BC

\begin{tabular}{ccccc}
\hline \multirow{2}{*}{$\begin{array}{c}\text { Concentration } \\
(\mathrm{ppmv})\end{array}$} & \multicolumn{5}{c}{$\mathrm{BC}$} \\
\cline { 2 - 5 } & $\begin{array}{c}K^{\prime} \\
\left(\mathrm{min}^{-1)}\right.\end{array}$ & $\begin{array}{c}t \\
(\mathrm{~min})\end{array}$ & $k$ & $R^{2}$ \\
\hline 20 & 0.1054 & 53.90 & 5.6810 & 0.9950 \\
\hline 50 & 0.1330 & 44.17 & 5.8750 & 0.9660 \\
\hline 100 & 0.1651 & 31.47 & 5.1968 & 0.9580 \\
\hline 200 & 0.1722 & 24.06 & 4.1436 & 0.9920 \\
\hline
\end{tabular}

\section{CONCLUSIONS}

In the present study, formaldehyde adsorption onto black bone char was investigated. To determine the breakthrough time and the equilibrium adsorption capacity of black bone char for formaldehyde adsorption, a continuous flow mode column loaded with black bone char was used. Isotherm models and Yoon and Nelson model were utilized to describe the adsorption process. As shown, the higher inlet concentration of formaldehyde was, the faster breakthrough time was, and the slope was gradually increased. Moreover, with the increase of formaldehyde concentration, the adsorption capacity (as $\mathrm{mg} / \mathrm{g}$ ) increased. The values of the correlation coefficients indicated that the Langmuir model was more suitable than the Freundlich model for formaldehyde adsorption onto black bone char. It is demonstrated that the agreement between the Yoon and Nelson model and the experimental data is high because of high correlation coefficients $\left(\mathrm{R}^{2}>0.9\right)$ for formaldehyde adsorption onto black bone char.

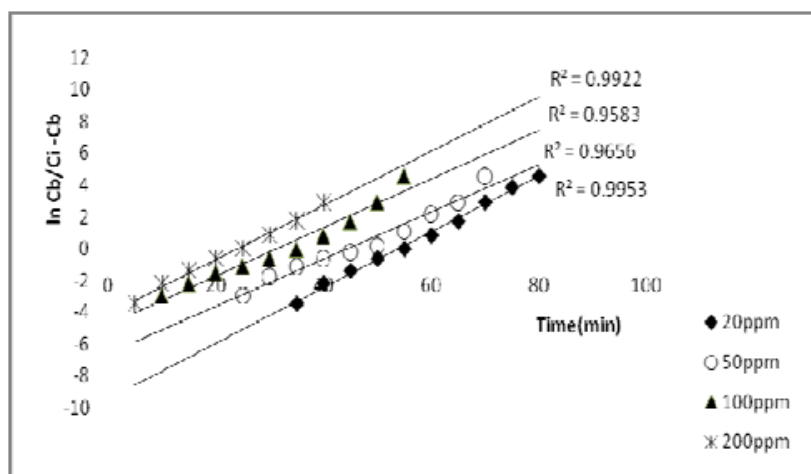

Fig.6. Typical plots of, $\ln [\mathrm{Cb} /(\mathrm{Ci}-\mathrm{Cb})]$ versus sampling time $(t)$ for formaldehyde adsorption on black bone char at $25^{\circ} \mathrm{C}$.

\section{ACKNOWLEDGMENT}

The authors wish to acknowledge the financial support of Tarbiat Modares University.

\section{REFERENCES}

[1] K.J. Lee, N. Shiratori, G.H. Lee, J. Miyawaki, I. Mochida, S-H.Yoon, and J. Jang, "Activated carbon nanofiber produced from electrospun polyacrylonitrile nanofiber as a highly efficient formaldehyde adsorbent" Carbon, Vol 4, pp. 4248-4255, December 2010.

[2] H. Rong, Z. Ryu, J. Zheng, and Y. Zhang, "Influence of heat treatment of rayon-based activated carbon fibers on the adsorption of formaldehyde" J. Colloid. Interf . Sci., Vol 261, pp. 207-212, May 2003.

[3] J.H.E. Arts, H. Muijser, C.F. Kuper, and R.A. Woutersen "Setting an indoor air exposure limit for formaldehyde: Factors of concern" Regul. Toxicol. Pharm., Vol 52, pp. 189-194, Nov. 2008.

[4] IARC; Monographs on the Evaluation of Carcinogenic Risks to Human, Vol. 88:Formaldehyde, 2-Butoxyethanol and 1-tert-Butoxy-2-propanol, World Health Organization, Lyon, 2006.

[5] Y, Liping, L, Zhenyan, J, Shi, H, Hu, and W, Shangguan, "Design consideration of photocatalytic oxidation reactors using $\mathrm{TiO} 2$-coated foam nickels for degrading indoor gaseous formaldehyde" Catalysis Today, Vol 126, pp.359, Augest 2007.

[6] S.W. Kang, B.H. Min, and S.S. Suh, Adsorption, Ion exchange, and catalysis, Environ Technol., Vol 83, pp. 17-23, 2000

[7] G. Vazquez, J. Gonzalez-Alvarez, A.I., Garcia, M.S. Freire, and G. Antorrena , Adsorption of phenol on formaldehyde-pretreated Pinus pinaster bark: Equilibrium and kinetics. Bioresource Technol., Vol 98, pp. 1535-1540, May 2007.

[8] A. Rezaee, Gh. Ghanizadeh, Gh. and Behzadiyannejad, "Adsorption of endotoxin from aqueous solution using bone char" Bull. Environ. Contam .Toxicol. Vol 82, pp.732-737, May 2008.

[9] W.T. Tsai, M.F. Hsieh, H.F. Sun, and S.F. "Adsorption of paraquat onto activated bleaching earth chien” Bull. Environ. Contam. Tooxicol. Vol 206, pp 557-562, Jun 2002.

[10] I. Smiciklas, S. Dimovic, M. Sljivic, and I. Plecas, “ Adsorption of toluene using hydroxyapatite” J. Environ. Sci. Eng. Vol 43, pp 73-81, December 2008.

[11] A. Honora, F.M. Plieva, and M. Hedstrom, " Structure of Bone char" J. Biotechnol. Vol. 118, pp 421-427, Feb 2008

[12] C.W. Cheung, C.K. Chan, J.F. Porter, and G. McKay, "Combined diffusion model for the sorption of cadmium, copper, and zinc ions onto bone char"Environ. Sci. Technol. Vol 35, pp 1530-1534, Augest 2001.

[13] Y.H. Yoon, and J.H. Nelson, “Application of gas adsorption kinetics. I: A theoretical model for respirator cartridge service life"Am. Ind. Hyg. Assoc. J. Vol.45, pp:509-516, 1984.

[14] L. Jing, L. Zhong, L. Bing, X. Qibin, and X. Hongxia," Effect of relative humidity on adsorption of formaldehyde on modified activated carbons" Chin. J. Chem. Eng., Vol: 16, pp 871-876, December 2008.

[15] J.Pei, J.S. Zhang, Chem. Eng. J. Vol:167, pp: 59-64, May 2011

[16] A. Shiue, W. Den, Y-H Kang, S-C Hu, G-T Jou, C.H. Lin, V. Hu, and S.I. Lin," Validation and application of adsorption breakthrough models for the chemical filters used in the make-up air unit (MAU) of a cleanroom. Build Environ Vol 46, PP 468-477, Feb. 2011 